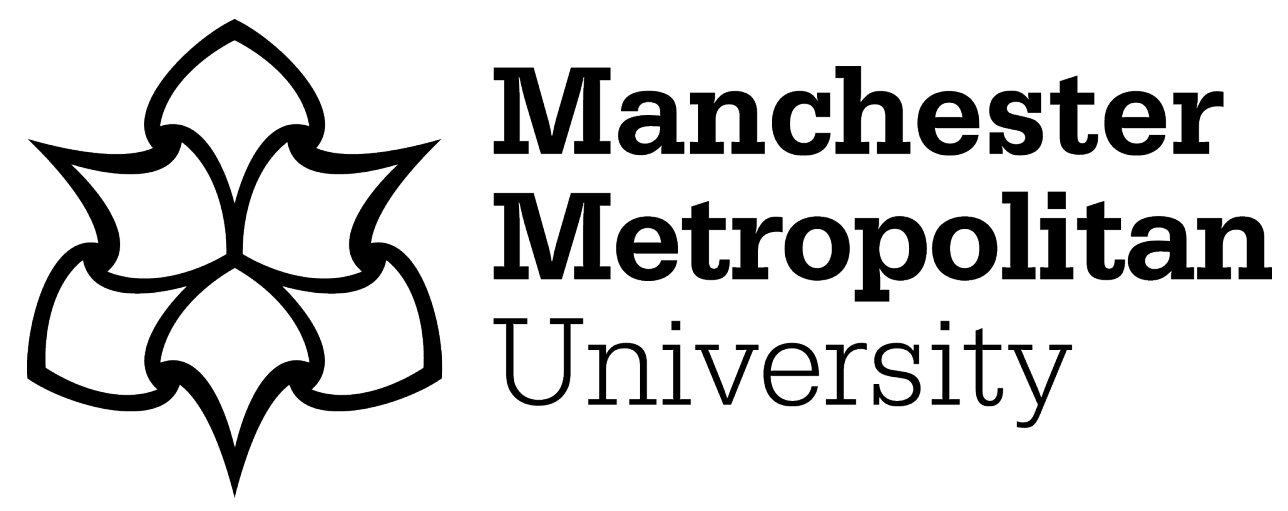

Sawkulycz, Xenia, Bradburn, Steven, Robinson, Andrew, Payton, Antony, Pendleton, Neil and Murgatroyd, Chris ORCID logoORCID: https://orcid.org/0000-0002-6885-7794 (2020) Regulation of Interleukin 6 by a polymorphic $\mathrm{CpG}$ within the frontal cortex in Alzheimer's disease. Neurobiology of Aging, 92. pp. 75-81. ISSN 0197-4580

Downloaded from: https://e-space.mmu.ac.uk/625566/

Version: Accepted Version

Publisher: Elsevier BV

DOI: https://doi.org/10.1016/j.neurobiolaging.2020.04.008

Please cite the published version 


\section{Regulation of Interleukin 6 by a polymorphic CpG within the frontal cortex in Alzheimer's disease}

2 Xenia Sawkulycz ${ }^{1}$, Steven Bradburn ${ }^{1}$, Andrew Robinson ${ }^{2}$ Antony Payton ${ }^{3}$, Neil Pendleton ${ }^{3}$, Chris 3 Murgatroyd $^{1 *}$

$4 \quad{ }^{1}$ Bioscience Research Centre, Manchester Metropolitan University, Manchester, United Kingdom.

$5 \quad{ }^{2}$ Faculty of Biology, Medicine and Health, School of Biological Sciences, Division of Neuroscience \& 6 Experimental Psychology, University of Manchester, Salford Royal Hospital, Salford, M6 8HD, UK.

$7{ }^{3}$ Division of Informatics, Imaging \& Data Sciences, School of Health Sciences, The University of 8 Manchester, M13 9PL

$9 *$ Dr Chris Murgatroyd, Bioscience Research Centre, Manchester Metropolitan University, Chester 10 Street, Manchester, United Kingdom, M1 5GD. Tel: (+44)1612471212. E-mail: 11 c.murgatroyd@mmu.ac.uk. 
28 The cytokine interleukin 6 (IL-6), has been linked to the pathogenesis of Alzheimer's disease (AD). This

29 is the first study to investigate the genetic and epigenetic interactions in the control of IL- 6 in human 30 brain and its relation to AD neuropathology in prefrontal cortex tissues from AD and controls genotyped 31 for the SNP -174 C/G rs1800795, a polymorphic CpG in which the G allele creates a CpG site. Within CC 32 homozygotes there were significantly higher brain levels of IL-6 protein compared to G allele carriers.

33 The $\mathrm{C}$ allele that resulted in an absence of methylation at a $\mathrm{CpG}$ also associated with significant changes 34 in methylation at neighbouring CpGs. Furthermore, there were differential significant differences in 35 methylation between $C C$ and $C G / G G$ at $C p G$ sites in the $A D$ and control groups. That DNA methylation 36 was shown to be altered in the brains by the presence of rs1800795, which further correlated with 37 protein levels suggests the presence of a polymorphic $\mathrm{CpG}$ and genetic-epigenetic interactions in the 38 regulation of $I L-6$ in the prefrontal cortex within AD brains.

39

40 Key words : Interleukin-6, DNA methylation, Alzheimer's disease, prefrontal cortex, neuroinflammation, 41 epigenetic 
43

44

45

46

47

48

49

50

\section{Introduction}

Interleukin 6 (IL-6) is a cytokine with both pro- and anti-inflammatory functions and shows both neuroprotective and -degenerative properties within the brain (Baune et al., 2012) IL-6 has a major role in chronic inflammation, and elevated levels are found in many inflammatory diseases (Gabay, 2006) including cognitive decline and Alzheimer's disease (AD) (Bradburn et al., 2018; Koyama et al., 2013; Lai et al., 2017). The development of $\beta$-amyloid plaques and tau within AD can induce microglia and astrocytes to secrete immune factors such as IL- 6 and vice versa, levels of IL- 6 are thought to increase the development of $\beta$-amyloid plaques and tau tangles with increased levels of IL-6 found in the formation of $\beta$-amyloid plaques and phosphorylated tau (Hüll et al., 1996; Quintanilla et al., 2004). The IL-6 polymorphism rs1800795, located in the promoter region -174 bp upstream of the transcriptional start site has been shown to regulate IL-6 expression (Falleti et al., 2010). However, the results of studies regarding the activity and effects of the polymorphism on plasma levels of these mediators and susceptibility to different diseases are contradictory. Rea et al. (Rea et al., 2003) in a study of octogenarian and nonagenarian subjects found that participants homozygotes for the $\mathrm{C}$ allele presented with higher plasma IL-6 levels, a finding supported by another study on individuals older than 80 years (Bruunsgaard et al., 2004). In contrast, a study of elderly women reported that the $G$ allele was associated with higher plasma IL-6 levels (Pereira et al., 2011). A meta-analysis of plasma IL-6 levels in healthy individuals found no significant association with this variant (Huang et al., 2013). In regard to transcriptional activity, in silico analysis and qRT-PCR on neuroblastoma specimens showed that the CC genotype correlated with higher level of IL-6 expression (Totaro et al., 2013). In regard to possible mechanisms, it has been demonstrated that the $\mathrm{G}>\mathrm{C}$ single nucleotide polymorphism (SNP) affects GATA1 binding to the IL-6 promoter, thereby linking this SNP to differential risk of inflammation-related diseases (Cole et al., 2010). Furthermore, the rs 1800795 is a polymorphic $\mathrm{CpG}$ with the $\mathrm{G}>\mathrm{C}$ disrupting a CpG site that could potentially be methylated to allow allele-specific epigenetic control.

The IL-6 -174 G/C polymorphism has been widely investigated in relation to the risk of inflammatoryrelated diseases. Four meta-analysis studies have investigated the $-174 \mathrm{G} / \mathrm{C}$ polymorphism and the risk of AD. Three reported a reduced risk with the C allele in CC homozygotes (Dai et al., 2012; Han et al., 2011; Qi et al., 2012) though, a more recent (2016) meta-analysis revealed that all genetic models (homozygote, CC vs. GG; heterozygote, GC vs. GG; dominant CC/GC vs. GG; recessive models, CC vs. GC/GG) were not associated with the risk of AD (Mun et al., 2016). A study investigating serum and brain IL-6 protein levels in AD patients genotyped for rs1800795, found significantly increased levels of plasma IL-6 in homozygous $C$ individuals compared to heterozygous and those homozygous for the $G$ allele, but only in AD patients and not controls. The group also reported an increase in IL-6 in the mid 
frontal cortex (Licastro et al., 2003) in participants homozygous for the $C$ allele, suggesting a possible impact of the AD pathology on IL-6 allele-specific regulation.

The expression of IL- 6 is known to be regulated by epigenetic mechanisms including DNA methylation. Nile et al. (Nile et al., 2008) found significantly lower DNA methylation within the IL-6 promoter in blood cells of patients suffering from rheumatoid arthritis. Dandrea et al. (Dandrea et al., 2009) found that the in vitro DNA demethylation, using 5-aza-2'-deoxycytidine, induced IL-6 expression that correlated reduced methylation in the IL-6 promoter. Poplutz et al. (Poplutz et al., 2014) in differentiating monocytic HL-60 cells showed that changes in methylation at CpGs in the IL-6 promoter correlated with IL-6 expression. Investigating AD brains, Nicolia et al. (Nicolia et al., 2017) showed a progressive decrease in DNA methylation at the IL-6 promoter with disease progression. However, fFew studies have investigated together the epigenetic, genetic, transcriptional and translational regulation of this cytokine within the brain in relation to AD. If rs1800795 acts as a polymorphic CpG then it would be important to investigate if it plays a role in $I L-6$ regulation in $A D$.

The aim of this study was to investigate mechanisms underlying the role of rs1800795 in the regulation of IL-6 within the brain and to understand how this may be a risk factor for AD. We studied human prefrontal cortex tissue for II-6 protein levels, gene expression and promoter DNA methylation to test the hypothesis that $\mathrm{G}$ and $\mathrm{C}$ alleles differentially regulate the activity of IL- 6 expression to understand the possible role of allele-specific regulation of IL-6 in AD.

\section{Materials and methods}

\subsection{Study population}

Fresh, frozen tissue was taken from superior frontal gyrus (Brodmann area 8) from donors through the Manchester Brain Bank. Ethical approval was granted from the Manchester Brain Bank Committee. Donors were participants of a large prospective cognitive ageing cohort known as The University of Manchester Age and Cognitive Performance Research Cohort (Rabbitt et al., 2004; Robinson et al., 2018) and included all those with brain material and available neuropathological data. All participants were white British (Supplementary Table 1). Stratification into AD neuropathology and control groups were based on neurofibrillary tangle stage (Braak), and neuritic plaque score (CERAD).

\subsection{Genotyping}

DNA were extracted from the pre-frontal cortex samples, as described previously (Bradburn et al., 2018), and genotyped for the rs1800795 polymorphism using the Kompetitive Allele-Specific PCR (KASP) assay (LGC Ltd) in reaction volumes of $10 \mu \mathrm{l}$ together with $5 \mathrm{ng}$ of DNA. This was run on a Stratagene MX3000P qPCR machine (Agilent) and results analysed using the MXPro software. 
108

109

110

111

112

113

114

115

116

117

118

119

120

121

122

123

124

125

126

127

128

129

130

131

132

133

134

135

136

137

138

139

\subsection{Protein quantification}

Approximately $100 \mathrm{mg}$ of prefrontal cortex tissue was lysed with RIPA buffer (Sigma - Aldrich) containing a protease inhibitor cocktail (Sigma - Aldrich). Protein concentration of IL-6 was determined using the high sensitivity human IL-6 ELISA kit (Abcam).

\section{$\underline{2.4}$ Gene expression analysis}

Brain tissue ( $\sim 30 \mathrm{mg}$ ) was extracted for RNA using TRIsure ${ }^{\mathrm{TM}}$ (Bioline, UK), and quantified using the Nanodrop 2000c (Thermo Scientific, Wilmington, USA). RNA samples were analyzed using the Agilent 2100 Bioanalyzer with RNA 6000 kits to give RNA integrity numbers (RIN values). The Tetro cDNA synthesis kit (Bioline, UK) was used to reverse transcribe total RNA $(2 \mu \mathrm{g})$ using random hexamers. Relative gene expression was analysed using qPCR with SensiFAST ${ }^{\top M}$ SYBR $^{\circledR}$ Lo-ROX kit (Bioline) with primers for IL-6 (F: GGTACATCCTCGACGGCATCT; R: GTGCCTCTTTGCTGCTTTCAC), b-ACTIN (F: CATCCTCACCCTGAAGTACC; R: ATAGCAACGTACATGGCTGG) and GAPDH (F: CCGCATCTTCTTTTGCGTCG; R: TGGAATTTGCCATGGGTGGA) that were run on a Stratagene Mx3000P qPCR system (Agilent) in duplicate. Relative gene expression, accounting for primer efficiencies and normalised to GAPDH and B-ACTIN, were determined using a geometric averaging method described by Vandesompele et al (Vandesompele et al., 2002).

\subsection{DNA methylation analysis}

Genomic DNA was extracted using the Isolate II Genomic DNA kit (Bioline) and 500 ng bisulfiteconverted using the EpiMark Bisulfite Conversion Kit (New England Biolabs). Primers were designed using the Pyromark Assay design software (Qiagen) used to amplify regions of the IL-6 promoter (F AAAAAGAAAGTAAAGGAAGAGTGG-Biotinylated; $\mathrm{R}: \quad$ CCTCAAACATCTCCAATCCTATATTTA; $\quad \mathrm{S}$ : AAACCTTATTAAAATTATACAATAT). PCRs were performed -using MyTaq HS mix PCR reagents (Bioline) with the following conditions: initial denaturation of $1 \mathrm{~min} 95^{\circ} \mathrm{C} ; 49 \mathrm{cycles}$ of $95^{\circ} \mathrm{C}$ for $15 \mathrm{sec}, 52.6^{\circ} \mathrm{C}$ for $15 \mathrm{sec}, 72^{\circ} \mathrm{C}$ for $10 \mathrm{~s}$; final extension of $72^{\circ} \mathrm{C}$ for $5 \mathrm{~min}$. The $\mathrm{L}-6$ promoter region analysed (>hg38_dna range $=$ chr7:22726826-22727526 5'pad=200 3'pad=500) contained 4 CpG sites or 3 depending on genotype (see Supplementary Figure 1). Amplicons were processed on the Qiagen Q24 Workstation and sequenced using the Sequecing primer AAACCTTATTAAAATTATACAATAT designed to analyse the region AACRTCCTTTAACATAACAA AACACAACTAAAAAAAAAAAT. Assays were performed in duplicate on the Qiagen Q24 pyrosequencer and included a control for complete bisulphite conversion (Dejeux et al., 2009):-

\section{$\underline{2.6}$ Statistical analyses}


The SPSS statistics software package (v25.0 for Windows; SPSS, Chicago, IL) was used for statistical analyses. Data was tested for normality using the Shapiro-Wilk test. Data determined to be normally distributed was presented as mean \pm standard deviation (SD) or median and $25^{\text {th }}-75^{\text {th }}$ percentiles if not normally distributed. IL-6 protein and IL-6 expression levels were analysed using a Mann-Whitney U test. A Kruskal Wallis test was used to analyse the significance of IL-6 protein levels between the neuropathological hallmarks CERAD and BRAAK.Methylation percentage among $\mathrm{CpG}$ sites were analysed using an independent T-test to compare between control and $A D$ that were defined as: Control (0-A CERAD; 0-2 Braak) AD (B CERAD; 3-5 Braak): excluding brains that did not fall into the catagories due to other pathologies and diagnoses (see Supplemental Table 1) there were $n=17$ control brains and $n=27$ AD samples. Correlations between protein, DNA methylation and gene expression of IL-6 were determined using Spearman's correlation test. A significance threshold of $P=<0.05$ was used.

\section{Results}

\subsection{Study population}

Clinical and pathological characteristics of the study population can be found in Table 1. IL-6 protein levels were compared between measures of AD neuropathology including BRAAK,THAL and CERAD. Importantly one data point with a value of $128.98 \mathrm{pg} / \mathrm{mg}$ (6x above the S.D.) was removed from all analyses. Samples that could not be classified into various staging were omitted from the anaysis. This revealed no significance differences between IL-6 protein levels between control and AD, and BRAAK $(p=0.564)$, THAL $(p=0.320)$ or CERAD $(p=0.719)$ staging (Figure 1$)$. IL-6 mRNA levels also did not differ between control and AD groups ( $p=0.713$ ) (Figure 2).

\section{2 rs1800795 polymorphism and IL-6 protein and mRNA levels}

Levels of IL- 6 total protein and relative IL- 6 gene expression were compared between the two different genotypes. This revealed that IL-6 protein levels in C homozygotes were significantly higher than the $\mathrm{G}$ allele carriers $p=0.034(C C(n=21)$ compared to $C G / G G(n=41))$. IL-6 gene expression however did not differ between genotypes $p=0.459$ (Figure 3); importantly, one data point with a value of 29.53 (4x above the S.D.) was removed from the analysis.

\subsection{DNA methylation at the IL-6 promoter}

IL-6 promoter methylation in the brains of homozygous $\mathrm{C}$ and heterozygous carriers (that contain an extra CpG (site 2)) was compared. While CpG site 1 methylation did not significantly differ $(p=0.708)$ 
between genotype groups, methylation at CpG site 3 was significantly lower in the G carriers $(p=0.0003$, while methylation at CpG site 4 was significantly higher in $G$ carriers $(p=<0.0001)$ (Figure 4). This suggests that the $G$ allele influences DNA methylation at the IL-6 promoter. When correlating CpG2 methylation in $\mathrm{G}$ carriers (the genotype that produces a $\mathrm{CpG}$ ), we observed that there was no significant association with either $I L-6$ expression $((p=0.445 ; n=28)$ or protein levels $(p=0.629 ; n=29)$. CpG 2 methylation was further compared between controls and AD patients and again no correlations were observed in protein and IL- 6 expression levels in either control or AD groups ( $p=0.805$ and 0.219 , respectively). Levels of CPG methylation at the IL-6 promoter were further analysed using an independent t-test for differences between controls and AD brains. Methylation between the control and $A D$ groups did not significantly differ at $C p G$ sites $1(p=0.241), 2(p=0.309)$ and $4(p=0.625)$, though CPG 3 showed a non-significant trend towards reduced methylation in $A D(P=0.052)$ (Figure 5). Spearman correlations between IL-6 protein levels and methylation at each CpG site for each genotype (CC $n=15)$ found no correlations at CpGs $1(p=0.436), 3(p=0.681)$ and $4(p=0.383)$. Similarly, there were no associations between IL-6 protein levels in CpG site $1(p=0.743), 3(p=0.666)$ and $4(p=0.530)$ in the CG/GG genotype group ( $n=29$ ). This indicates that methylation levels are not correlated with protein levels when stratified by genotype. A comparison was preformed between each CpG site and IL-6 gene expression levels stratified into genotype to determine if methylation levels correspond to the levels of expression. No correlations were found between IL-6 gene expression with CpG site $1(p=0.621), 3$ $(p=0.823)$ and $4(p=0.784)$ in the CC genotype group $(n=13)$ and no associations were found between IL-6 gene expression levels in CpG site $1(p=0.530), 3(p=0.445)$ and $4(p=0.09)$ in the CG/GG genotype group ( $n=28$ ). This shows that $I L-6$ gene expression is not regulated by DNA methylation within the different genotypes.

Considering genotype influenced methylation at $\mathrm{CpG}$ sites 3 and 4 and $\mathrm{CpG} 3$ showed a nonsignificant trend to reduced methylation in the AD brains, we performed an Anova between $A D$ and control brains for DNA methylation at these two sites between the genotypes. This revealed significant differences in methylation between $C C$ and $C G / G G$ at $C p G$ sites 3 and 4 in the $A D$ group $(p=0.003$ and 0.000 ) and $C p G$ site 4 in the control group ( $p=0.002$ ) suggesting that the rs 1800795 genotype regulates DNA methylation at neighbouring CpGs in the presence of AD pathology.

\section{Discussion}

In human prefrontal cortex we found that the rs 1800795 polymorphism was associated with differential methylation of the IL-6 promoter and IL-6 protein levels. Specifically, we found higher levels of IL-6 protein in $\mathrm{C}$ homozygous individuals compared to those carrying at least one copy of the $\mathrm{G}$ allele. This 
suggests levels of IL-6 in brain tissues may be regulated by the IL-6 rs1800795 polymorphism. Importantly, the $\mathrm{G}$ allele produces a $\mathrm{CpG}$ site that we found can be methylated and influences local DNA methylation at CpG sites 3 and 4 in the IL- 6 promoter, indicating that the rs 1800795 genotype has an effect upon epigenetic regulation of the gene in the prefrontal cortex. Finally, we found reduced and increased levels of DNA methylation at CpGs 3 and 4 respectively in AD brains compared to control suggesting a gene-environment interaction between the rs1800795 polymorphism and epigenetic regulation of IL-6. IL-6 has been detected in the brains of AD patients, particularly in those with early stages of amyloid deposition and plaque formation (Gruol and Nelson, 1997). Further, the expression levels of IL-6 mRNA, from a study in transgenic mouse brains, were found to increase during AD pathology (López-González et al., n.d.). In our studies we did not find such a pattern. However, a previous study on a group of 46 AD brains showed that levels of IL- 6 were higher in CC genotypes compared to CG and GG (Licastro et al., 2003), similar to our data. This may account for the similarity between $A D$ and control if genotype is not considered. However, when we did control for genotype there were still no differences in IL-6 expression between control and AD brains (data not shown). In addition, RNA integrity numbers (RIN), used to measure the quality of the mRNA, were on the lower side in this study and this related to variations in postmortem times (Supplementary Table 1). This may also have impacted the RNA analyses.

Our finding that IL-6 protein levels were lower in those prefrontal cortex samples in individuals with genotypes containing the $\mathrm{G}$ allele is in agreement with the only previous study that has tested this (Licastro et al., 2003) suggesting a regulatory role of this polymorphism. Additional studies of serum from juvenile chronic arthritis patients (Fishman et al., 1998), LPS-stimulated leukocytes (Rivera-Chavez et al., 2003), and 2 genetically different cell lines (Terry et al., 2000) have indicated that rs 1800795 might affect $I L-6$ gene regulation by modulating unspecified transcription factors. Cole and colleagues (2010) (Cole et al., 2010) using computational prediction of GxE to investigate a 1000bp region of the IL-6 promoter reported rs 1800795 to be the sole functionally active regulatory SNP that was predicted to show high-affinity binding of the GATA-1 transcription factor that would be abrogated by the G>C transversion. This was supported using allele-specific chromatin immunoprecipitation assays in macrophages. Although binding was at very low levels at the IL-6 GATA-1 element, this was significantly increased for the $\mathrm{G}$ allele compared to the $\mathrm{C}$ allele in response to norepinephrine and this was further mediated by beta-adrenergic activation of the protein kinase A (PKA) signalling pathway. This study also used luciferase reporter assays in B lymphocytes to show that GATA-1 repressed IL-6 expression following the addition of norepinephrine. Other independent studies have shown that GATA-1 at other genes in neuronal cells can act as a repressor, for example at the $\mathrm{\gamma}$-secretase gene in Down Syndrome brains with AD pathology (Chu et al., 2016). Interestingly, a published abstract reported increased levels 
of GATA-1 protein in prefrontal cortex of AD brains compared to controls (Wang et al., 2014).

239

240

241

243

244

245

246

247

248

249

250

251

252

253

254

255

256

257

258

259

260

261

262

263

264

265

266

267

268

269

270

271 Furthermore, Amyloid $\beta$-peptide has been shown to inhibit PKA signalling pathways (Vitolo et al., 2002) that is itself regulated by beta-adrenergic signalling (Bussiere et al., 2017).

The 174G $>C$ IL-6 promoter polymorphism (rs1800795) has been associated with numerous inflammatory-related diseases including systemic onset juvenile arthritis, systemic lupus erythamatosis, Sjögren's syndrome, AD, type II diabetes mellitus and cardiovascular disease (Bruunsgaard et al., 2004; Dai et al., 2012; Fishman et al., 1998; Hulkkonen et al., 2001; Humphries et al., 2001; Schotte et al., 2001). Though studies have documented a direct functional effect of this variant on promoter activity, the association of this polymorphism with IL-6 levels is not consistent, with some studies showing higher IL-6 levels with the C allele (e.g. in plasma following coronary bypass (Brull et al., 2001), some with G (e.g in patients with multivessel coronary artery (Burzotta et al., 2001)) and some with neither (e.g. in patients with and without coronary artery disease (Nauck et al., 2002)). One possible explanation for these differences may be that additional functional variation may exist from allele-dependent epigenetic modifications. Another aspect to consider is that though methylated cytosines are found primarily at $\mathrm{CpG}$ dinucleotides, they are also found at non- $\mathrm{CpG}$ sites $(\mathrm{CpH})$, such as $\mathrm{CpA}, \mathrm{CpT}$, and CpC. Although the function and mechanisms of this type of methylation are not fully understood, studies show the presence of $\mathrm{CpH}$ methylation in human brains, and in vitro studies show $\mathrm{mCpHs}$ can repress transcription (Guo et al., 2014). As our study did test for $\mathrm{CpH}$ methylation, we cannot rule out the role of this epigenetic modification between the genotypes or indeed $\mathrm{CpC}$ methylation in the CC genotype. Further, that our primers were specific to bisulphite DNA, we also cannot rule-out whether $\mathrm{CpH}$ methylation might have effected binding of primers and if hypermethylated sequences where $\mathrm{CpN}$ are also methylated, might have led to underestimating also $\mathrm{CpG}$ methylation.

The role of DNA methylation in the regulation of $I L-6$ is well documented. For example in rheumatoid arthritis, DNA methylation at an IL-6-related CpG was altered in affected patients, and a negative relationship between DNA methylation and IL-6 mRNA levels was observed, suggesting a DNA methylation-dependent regulation of IL-6 transcription (Nile et al., 2008). A further study in AD brains has shown a progressive decrease in DNA methylation at the IL-6 promoter with disease progression (Nicolia et al., 2017). Here we show that rs1800795 alters a CpG site leading to changes in DNA methylation. We therefore predict that this adds a further level of regulation of the gene for this cytokine within the AD brain. Interestingly, we see a significant difference in methylation between genotypes in $A D$ and controls. We suggest that changes in methylation during $A D$ progression, dependent on genotype, together with alterations in transcription factors such as GATA-1, lead to GXE interactions at which an allele becomes a risk factor dependent on disease state. For example, binding of GATA-1 has been shown to be influenced by DNA methylation, such as at the EKLF promoter (Li et 
al., 2018) and increased methylation at the $I L-6$ promoter has been linked to increased binding of the transcriptional epigenetic repressor MeCP2 (Dandrea et al., 2009).

\section{Conclussion}

In conclusion, we report that the regulation of IL- 6 within the prefrontal cortex is influenced by a SNP previously associated with $A D$ that alters DNA methylation and which may influence AD risk. These results add further evidence for a genetic-epigenetic and possible gene-environment regulation of the IL-6 gene within the AD brain.

\section{Abbreviations}

IL-6, Interleukin 6; SNP, single nucleotide polymorphism; Alzheimer's disease, AD;

\section{Declarations}

Ethics approval and consent to participate: Ethical approval was granted from the Manchester Brain Bank Committee; Consent for publication: All authors have seen this final MS and give consent for publication; Availability of data and material: Data is available upon request; Competing interests: The authors have no conflict of interests to report; Funding: This study was funded through the MMU; Authors' contributions: $\mathrm{CM}, \mathrm{XS}, \mathrm{SB}, \mathrm{NP}, \mathrm{AP}$ and $\mathrm{AR}$ devised the experiment; XS performed the experiments; $\mathrm{CM}, \mathrm{XS}$ and $\mathrm{SB}$ analysed the data and wrote the paper together with guidance from NP, AP and AR. Acknowledgements: none.

\section{References}

Baune, B.T., Konrad, C., Grotegerd, D., Suslow, T., Birosova, E., Ohrmann, P., Bauer, J., Arolt, V., Heindel, W., Domschke, K., Schöning, S., Rauch, A. V, Uhlmann, C., Kugel, H., Dannlowski, U., 2012. Interleukin-6 gene (IL-6): a possible role in brain morphology in the healthy adult brain. J. Neuroinflammation 9, 567. https://doi.org/10.1186/1742-2094-9-125

Bradburn, S., McPhee, J., Bagley, L., Carroll, M., Slevin, M., Al-Shanti, N., Barnouin, Y., Hogrel, J.Y., Pääsuke, M., Gapeyeva, H., Maier, A., Sipilä, S., Narici, M., Robinson, A., Mann, D., Payton, A., 
Pendleton, N., Butler-Browne, G., Murgatroyd, C., 2018. Dysregulation of C-X-C motif ligand 10 during aging and association with cognitive performance. Neurobiol. Aging 63, 54-64. https://doi.org/10.1016/j.neurobiolaging.2017.11.009

Brull, D.J., Montgomery, H.E., Sanders, J., Dhamrait, S., Luong, L., Rumley, A., Lowe, G.D., Humphries, S.E., 2001. Interleukin-6 gene -174g\&gt;c and -572g\&gt;c promoter polymorphisms are strong predictors of plasma interleukin-6 levels after coronary artery bypass surgery. Arterioscler. Thromb. Vasc. Biol. 21, 1458-63.

Bruunsgaard, H., Christiansen, L., Pedersen, A.N., Schroll, M., Jørgensen, T., Pedersen, B.K., 2004. The IL-6 -174G\&gt;C polymorphism is associated with cardiovascular diseases and mortality in 80year-old humans. Exp. Gerontol. 39, 255-61. https://doi.org/10.1016/j.exger.2003.10.012

Burzotta, F., lacoviello, L., Di Castelnuovo, A., Glieca, F., Luciani, N., Zamparelli, R., Schiavello, R., Donati, M.B., Maseri, A., Possati, G., Andreotti, F., 2001. Relation of the -174 G/C polymorphism of interleukin-6 to interleukin-6 plasma levels and to length of hospitalization after surgical coronary revascularization. Am. J. Cardiol. 88, 1125-8.

Bussiere, R., Lacampagne, A., Reiken, S., Liu, X., Scheuerman, V., Zalk, R., Martin, C., Checler, F., Marks, A.R., Chami, M., 2017. Amyloid $\beta$ production is regulated by $\beta 2$-adrenergic signalingmediated post-translational modifications of the ryanodine receptor. J. Biol. Chem. 292, 1015310168. https://doi.org/10.1074/jbc.M116.743070

Chu, J., Wisniewski, T., Praticò, D., 2016. GATA1-mediated transcriptional regulation of the $\gamma$-secretase activating protein increases A $\beta$ formation in Down syndrome. Ann. Neurol. 79, 138-43. https://doi.org/10.1002/ana.24540

Cole, S.W., Arevalo, J.M.G., Takahashi, R., Sloan, E.K., Lutgendorf, S.K., Sood, A.K., Sheridan, J.F., Seeman, T.E., 2010. Computational identification of gene-social environment interaction at the human IL6 locus. Proc. Natl. Acad. Sci. U. S. A. 107, 5681. https://doi.org/10.1073/PNAS.0911515107

Dai, L., Liu, D., Guo, H., Wang, Y., Bai, Y., 2012. Association between polymorphism in the promoter region of Interleukin 6 (-174 G/C) and risk of Alzheimer's disease: a meta-analysis. J. Neurol. 259, 414-419. https://doi.org/10.1007/s00415-011-6164-0

Dandrea, M., Donadelli, M., Costanzo, C., Scarpa, A., Palmieri, M., 2009. MeCP2/H3meK9 are involved in IL-6 gene silencing in pancreatic adenocarcinoma cell lines. Nucleic Acids Res. 37, 6681-90. https://doi.org/10.1093/nar/gkp723 
Dejeux, E., El abdalaoui, H., Gut, I.G., Tost, J., 2009. Identification and quantification of differentially methylated loci by the pyrosequencing technology. Methods Mol. Biol. 507, 189-205.

$$
\text { https://doi.org/10.1007/978-1-59745-522-0_15 }
$$

Falleti, E., Fabris, C., Vandelli, C., Colletta, C., Cussigh, A., Smirne, C., Fontanini, E., Cmet, S., Minisini, R., Bitetto, D., Toniutto, P., Pirisi, M., 2010. Genetic polymorphisms of interleukin-6 modulate fibrosis progression in mild chronic hepatitis C. Hum. Immunol. 71, 999-1004. https://doi.org/10.1016/j.humimm.2010.06.006

Fishman, D., Faulds, G., Jeffery, R., Mohamed-Ali, V., Yudkin, J.S., Humphries, S., Woo, P., 1998. The effect of novel polymorphisms in the interleukin-6 (IL-6) gene on IL-6 transcription and plasma IL-6 levels, and an association with systemic-onset juvenile chronic arthritis. J. Clin. Invest. 102, 1369-76. https://doi.org/10.1172/JCI2629

Gabay, C., 2006. Interleukin-6 and chronic inflammation. Arthritis Res. Ther. 8 Suppl 2, S3. https://doi.org/10.1186/ar1917

Gruol, D.L., Nelson, T.E., 1997. Physiological and pathological roles of interleukin-6 in the central nervous system. Mol. Neurobiol. 15, 307-339. https://doi.org/10.1007/BF02740665

Guo, J.U., Su, Y., Shin, J.H., Shin, J., Li, H., Xie, B., Zhong, C., Hu, S., Le, T., Fan, G., Zhu, H., Chang, Q., Gao, Y., Ming, G.L., Song, H., 2014. Distribution, recognition and regulation of non-CpG methylation in the adult mammalian brain. Nat. Neurosci. 17, 215-222. https://doi.org/10.1038/nn.3607

Han, X.-M., Wang, C.-H., Sima, X., Liu, S.-Y., 2011. Interleukin-6-174G/C polymorphism and the risk of Alzheimer's disease in Caucasians: A meta-analysis. Neurosci. Lett. 504, 4-8. https://doi.org/10.1016/j.neulet.2011.06.055

Huang, M., Wang, L., Ma, H., Wang, J., Xiang, M., 2013. Lack of an Association Between Interleukin-6 -174G/C Polymorphism and Circulating Interleukin-6 Levels in Normal Population: A MetaAnalysis. DNA Cell Biol. 32, 654-664. https://doi.org/10.1089/dna.2013.2148

Hulkkonen, J., Pertovaara, M., Antonen, J., Pasternack, A., Hurme, M., 2001. Elevated interleukin-6 plasma levels are regulated by the promoter region polymorphism of the IL6 gene in primary Sjögren's syndrome and correlate with the clinical manifestations of the disease. Rheumatology (Oxford). 40, 656-61. https://doi.org/10.1093/rheumatology/40.6.656

Hüll, M., Berger, M., Volk, B., Bauer, J., 1996. Occurrence of interleukin-6 in cortical plaques of Alzheimer's disease patients may precede transformation of diffuse into neuritic plaques. Ann. 
364

Humphries, S.E., Luong, L.A., Ogg, M.S., Hawe, E., Miller, G.J., 2001. The interleukin-6 -174 G/C promoter polymorphism is associated with risk of coronary heart disease and systolic blood pressure in healthy men. Eur. Heart J. 22, 2243-52. https://doi.org/10.1053/euhj.2001.2678

Koyama, A., O’Brien, J., Weuve, J., Blacker, D., Metti, A.L., Yaffe, K., 2013. The Role of Peripheral Inflammatory Markers in Dementia and Alzheimer's Disease: A Meta-Analysis. Journals Gerontol. Ser. A Biol. Sci. Med. Sci. 68, 433-440. https://doi.org/10.1093/gerona/gls187

Lai, K.S.P., Liu, C.S., Rau, A., Lanctôt, K.L., Köhler, C.A., Pakosh, M., Carvalho, A.F., Herrmann, N., 2017. Peripheral inflammatory markers in Alzheimer's disease: a systematic review and meta-analysis of 175 studies. J. Neurol. Neurosurg. Psychiatry 88, 876-882. https://doi.org/10.1136/jnnp2017-316201

Li, Y., Liu, D., Li, Z., Zhang, X., Ye, Y., Liu, Q., Shen, J., Chen, Z., Huang, H., Liang, Y., Han, X., Liu, J., An, X., Mohandas, N., Xu, X., 2018. Role of tissue-specific promoter DNA methylation in regulating the human EKLF gene. Blood Cells. Mol. Dis. 71, 16-22. https://doi.org/10.1016/j.bcmd.2018.01.004

Licastro, F., Grimaldi, L.M.E., Bonafè, M., Martina, C., Olivieri, F., Cavallone, L., Giovanietti, S., Masliah, E., Franceschi, C., 2003. Interleukin-6 gene alleles affect the risk of Alzheimer's disease and levels of the cytokine in blood and brain. Neurobiol. Aging 24, 921-6.

López-González, I., Schlüter, A., ... E.A.-... of N.\&, 2015, undefined, n.d. Neuroinflammatory signals in Alzheimer disease and APP/PS1 transgenic mice: correlations with plaques, tangles, and oligomeric species. academic.oup.com.

Mun, M.-J., Kim, J.-H., Choi, J.-Y., Jang, W.-C., 2016. Genetic polymorphisms of interleukin genes and the risk of Alzheimer's disease: An update meta-analysis. Meta gene 8, 1-10. https://doi.org/10.1016/j.mgene.2016.01.001

Nauck, M., Winkelmann, B.R., Hoffmann, M.M., Böhm, B.O., Wieland, H., März, W., 2002. The interleukin-6 G(-174)C promoter polymorphism in the LURIC cohort: no association with plasma interleukin-6, coronary artery disease, and myocardial infarction. J. Mol. Med. (Berl). 80, 507-13. https://doi.org/10.1007/s00109-002-0354-2

Nicolia, V., Cavallaro, R.A., López-González, I., Maccarrone, M., Scarpa, S., Ferrer, I., Fuso, A., 2017. DNA Methylation Profiles of Selected Pro-Inflammatory Cytokines in Alzheimer Disease. J. Neuropathol. Exp. Neurol. 76, nlw099. https://doi.org/10.1093/jnen/nlw099 
Nile, C.J., Read, R.C., Akil, M., Duff, G.W., Wilson, A.G., 2008. Methylation status of a single CpG site in the IL6 promoter is related to IL6 messenger RNA levels and rheumatoid arthritis. Arthritis Rheum. 58, 2686-93. https://doi.org/10.1002/art.23758

Pereira, D.S., Garcia, D.M., Narciso, F.M.S., Santos, M.L.A.S., Dias, J.M.D., Queiroz, B.Z., Souza, E.R., Nóbrega, O.T., Pereira, L.S.M., 2011. Effects of 174 G/C polymorphism in the promoter region of the interleukin-6 gene on plasma IL-6 levels and muscle strength in elderly women. Brazilian J. Med. Biol. Res. = Rev. Bras. Pesqui. medicas e Biol. 44, 123-9.

Poplutz, M.K., Wessels, I., Rink, L., Uciechowski, P., 2014. Regulation of the Interleukin-6 gene expression during monocytic differentiation of HL-60 cells by chromatin remodeling and methylation. Immunobiology 219, 619-26. https://doi.org/10.1016/j.imbio.2014.03.016

Qi, H.-P., Qu, Z.-Y., Duan, S.-R., Wei, S.-Q., Wen, S.-R., Bi, S., 2012. IL-6-174 G/C and -572 C/G polymorphisms and risk of Alzheimer's disease. PLoS One 7, e37858. https://doi.org/10.1371/journal.pone.0037858

Quintanilla, R.A., Orellana, D.I., González-Billault, C., Maccioni, R.B., 2004. Interleukin-6 induces Alzheimer-type phosphorylation of tau protein by deregulating the cdk5/p35 pathway. Exp. Cell Res. 295, 245-57. https://doi.org/10.1016/j.yexcr.2004.01.002

Rabbitt, P.M.A., Mclnnes, L., Diggle, P., Holland, F., Bent, N., Abson, V., Pendleton, N., Horan, M., 2004. The University of Manchester Longitudinal Study of Cognition in Normal Healthy Old Age, 1983 through 2003. Aging, Neuropsychol. Cogn. 11, 245-279. https://doi.org/10.1080/13825580490511116

Rea, I.M., Ross, O.A., Armstrong, M., McNerlan, S., Alexander, D.H., Curran, M.D., Middleton, D., 2003. Interleukin-6-gene C/G 174 polymorphism in nonagenarian and octogenarian subjects in the BELFAST study. Reciprocal effects on IL-6, soluble IL-6 receptor and for IL-10 in serum and monocyte supernatants. Mech. Ageing Dev. 124, 555-561. https://doi.org/10.1016/S00476374(03)00036-8

Rivera-Chavez, F.A., Peters-Hybki, D.L., Barber, R.C., O’Keefe, G.E., 2003. Interleukin-6 promoter haplotypes and interleukin-6 cytokine responses. Shock 20, 218-23. https://doi.org/10.1097/01.SHK.0000079425.52617.DB

Robinson, A.C., Davidson, Y.S., Horan, M.A., Pendleton, N., Mann, D.M.A., 2018. Pathological Correlates of Cognitive Impairment in The University of Manchester Longitudinal Study of Cognition in Normal Healthy Old Age. J. Alzheimer's Dis. 64, 483-496. 
426

427

428

429

430

Schotte, H., Schlüter, B., Rust, S., Assmann, G., Domschke, W., Gaubitz, M., 2001. Interleukin-6 promoter polymorphism (--174 G/C) in Caucasian German patients with systemic lupus erythematosus. Rheumatology (Oxford). 40, 393-400. https://doi.org/10.1093/rheumatology/40.4.393

Terry, C.F., Loukaci, V., Green, F.R., 2000. Cooperative Influence of Genetic Polymorphisms on Interleukin 6 Transcriptional Regulation. J. Biol. Chem. 275, 18138-18144. https://doi.org/10.1074/jbc.M000379200

Totaro, F., Cimmino, F., Pignataro, P., Acierno, G., De Mariano, M., Longo, L., Tonini, G.P., Iolascon, A., Capasso, M., 2013. Impact of Interleukin-6-174 G\&gt;C Gene Promoter Polymorphism on Neuroblastoma. PLoS One 8, e76810. https://doi.org/10.1371/journal.pone.0076810

Vandesompele, J., De Preter, K., Pattyn, F., Poppe, B., Van Roy, N., De Paepe, A., Speleman, F., 2002. Accurate normalization of real-time quantitative RT-PCR data by geometric averaging of multiple internal control genes. Genome Biol. 3, RESEARCH0O34.

Vitolo, O. V., Sant'Angelo, A., Costanzo, V., Battaglia, F., Arancio, O., Shelanski, M., 2002. Amyloid peptide inhibition of the PKA/CREB pathway and long-term potentiation: Reversibility by drugs that enhance cAMP signaling. Proc. Natl. Acad. Sci. 99, 13217-13221. https://doi.org/10.1073/pnas.172504199

Wang, J., Zhao, W., Freire, D., Ho, L., Pasinetti, G.M., 2014. NOVEL ROLE OF THE DEPRESSIONASSOCIATED GATA1 TRANSCRIPTION FACTOR IN ALZHEIMER'S DISEASE. Alzheimer's Dement. 10, P332. https://doi.org/10.1016/j.jalz.2014.05.315 
Figure 1 - IL-6 protein levels between different AD neuropathology stages. A. IL-6 protein levels did not significantly differ between control $(n=17)$ and $A D(n=24)(p=0.784)$. B. IL-6 protein levels were not found to be significantly different between BRAAK staging $(P=0.564) n=61$. C. No significant difference was found between IL-6 protein levels and THAL grouping $(p=0.320) n=62$. D. No significant difference was found between IL-6 protein levels and CERAD stages $(p=0.719) n=62$. Plots represent median and $25^{\text {th }}-75^{\text {th }}$ percentiles with individual plots of each samples shown.

Figure 2 - IL-6 mRNA_levels between Control and AD. IL-6 mRNA levels in control group $(n=17)$ and AD group $(n=24)$ were not significant $(p=0.749)$. Plots represent median and $25^{\text {th }}-75^{\text {th }}$ percentiles with individual plots of each samples shown.

459

Figure 3 - Protein and mRNA levels of IL-6 between rs1800795 genotypes. A. IL-6 protein levels were significantly higher in CC ( $n=21)$ compared to CG/GG ( $n$ 41) ( $p=0.034)$ genotypes. B. IL-6 mRNA levels between CC $(n=23)$ and $C G / G G(n=41)$ genotypes do not significantly differ $(p=0.459)$. Plots present median and $25^{\text {th }}-75^{\text {th }}$ percentiles with individual plots of all samples shown.

Figure 4 - DNA Methylation at the IL-6 promoter between rs1800795 genotypes. CpG site 1 methylation did not significantly differ between genotypes ( $p=0.708$ ). CpG site 2 (only present in the $G$ allele carriers) did not differ. CpG site 3 methylations significantly different between genotypes CC and CG/GG $p=$ 0.0003. CpG site 4 methylation significantly different in genotypes ( $p=<0.0001)$. CC ( $n 15), C G(n 27)$ and $G G(n=3)$ error bars represent standard deviation.

471 Figure 5 - DNA methylation levels at the IL-6 promoter in control and AD brains. DNA methylation at CpG sites $1(p=0.241), 3(p=0.052)$ and $4(p=0.625)$ (control $n=8 ; A D n=17)$ and $C p G$ site $2(p=0.309)$ (control $n=5 ; A D n=10)$. Error bars represent standard deviation. 